\title{
COMPARATIVE STUDY ON GROWTH AND PHOTOSYNTHETIC PIGMENT DYNAMICS OF TWO MICROALGAE UNDER THE INFLUENCE OF WATER POLLUTION WITH THE HERBICIDE GLUFOSINATE
}

\author{
SEBASTIAN RADU CRISTIAN PLUGARU ${ }^{\mathrm{a}}$, LASZLO FODORPATAKI ${ }^{\mathrm{b}}$, \\ MIHAELA ORBAN $^{\mathrm{a}}$, ANCA SARB $^{\mathrm{c}}$, BERNAT TOMPA ${ }^{\mathrm{b}}$, BALAZS KOVACS $^{\mathrm{b}}$
}

\begin{abstract}
The aim of the study is to compare biochemical and physiological reactions of two related species of green microalgae (Scenedesmus acuminatus and Scenedesmus opoliensis), both considered suitable for bioindication and remediation of aquatic environments polluted with herbicides. Monoalgal axenic cultures were treated for 10 days under controlled conditions with different concentrations (from $0.1 \mu \mathrm{M}$ to $100 \mu \mathrm{M}$ ) of glufosinate (a nonselective contact herbicide that inhibits glutamine synthase activity, thus disturbing photorespiration, inhibiting photosynthetic carbon assimilation, and generating ammonium excess in plant cells). $S$. opoliensis was found to be a better indicator of adverse effects of glufosinate than $S$. acuminatus. Changes in the ground chlorophyll fluorescence (reflecting light energy harvesting capacity), in cell division rate and in chlorophyll-a content may be early, costeffective and sensitive markers of herbicide impact on microalgal communities inhabiting polluted water. Our results bring new data concerning the need of selection among related test organisms based on differentiated tolerance, as well as concerning biochemical parameters suitable for evaluation of water pollution impact when organic xenobiotics accumulate in aquatic environments. Thus, the presented results may be applied in optimizing bioindication of water quality using microalgae, and in treatment of wastewater polluted due to agricultural practices.
\end{abstract}

Keywords: bioindication, chlorophylls, glufosinate, herbicide, water pollution

\footnotetext{
a Technical University of Cluj-Napoca, Faculty of Materials and Environmental Engineering, 103-105 Muncii Bd., RO-400641, Cluj-Napoca, Romania.

* Corresponding author: sebastian.plugaru@yahoo.com

${ }^{b}$ Babeş-Bolyai University, Faculty of Biology and Geology, 1 M. Kogălniceanu St., RO400084, Cluj-Napoca, Romania.

${ }^{c}$ Technical University of Cluj-Napoca, Faculty of Machine Building, 103-105 Muncii Bd., RO400641, Cluj-Napoca, Romania
} 
S. R. C. PLUGARU, L. FODORPATAKI, M. ORBAN, A. SARB, B. TOMPA, B. KOVACS

\section{INTRODUCTION}

Even though there are many attempts to replace xenobiotic pesticides with environmental-friendly biological compounds (e.g. certain secondary metabolites of plants and micro-organisms), modern agriculture cannot entirely dispense of chemically synthesized herbicides in order to ensure sufficiently high crop production under various conditions in which several weeds compete with cultivated plants for sunlight, for water and inorganic nutrient reserves of the soil. Herbicides are synthetic organic compounds which may persist over time in the aqueous solution of agricultural soils and finally accumulate in continental still waters where they reach concentrations which are highly toxic to all living organisms of the aquatic ecosystems. Planktonic microalgae, as the mostly widespread primary producers in these polluted waters are the main targets of the influence of herbicides, because they live as plants, so their physiological processes are directly damaged by herbicides. Furthermore, their metabolic plasticity and high functional adaptability sequestration, biocon-centration and biotransformation of herbicides, thus algae have a crucial contribution to decontamination of water polluted with organic xenobiotics $[1,17]$.

Among the various herbicides which may inhibit seed germination, cell division, photosynthesis, photorespiration, specific enzyme activities involved in unsaturated fatty acid synthesis, in amino acid synthesis, in production of chlorophylls and carotenoid pigments, or may disturb plant developmental processes by being hormone analogues [19], glufosinate (the ammonium salt of the formerly commercialized phosphinotricine, i. e. ammonium-(3-amino-3-car-boxypropyl)-methyl phosphinate) is one of the most largely used non-selective contact herbicides for various crops over the world (e. g. as a crop desiccant for harvesting in case of potato, canola, maize, spring wheat, or directly disposed on the leaves of weed species before the vegetation period of lettuce, beans, pea, grape, apple and other fruit trees). It inhibits the enzymatic activity of glutamine synthase, thus preventing the formation of a universal proteinogenic amino acid and leading to accumulation of toxic amounts of ammonia in plant cells. Finally, it inhibits the peroxisomal phase of photo-respiration in green leaf cells, by feed-back regulation it disturbs both the oxygenase and the carboxylase activities of Rubisco as the key enzyme in carbon dioxide fixation, it blocks photosynthesis and it induces damages in biological membranes, impairing their selective permeability [2]. These cumulated changes lead to the death of the plants which took up the herbicide. For several crop species, glufosinate-tolerant cultivars were created through genetic transformation (mainly by overexpression of the gene encoding for glutamine synthase), 
and their agricultural field is systematically treated with the herbicide. Some plants may develop a natural tolerance to glufosinate, based on its biotransformation through $\mathrm{N}$-acetylation [13].

Its influence on biochemical and metabolic parameters of green microalgae living in water ponds surrounded by agricultural terrains is poorly documented in the literature, many experimental data are controversial because of the use of different algal species and local varieties as test organisms and because of differences in experimental conditions and in methods of evaluation [2]. These are the main reasons why we proposed to compare the reactions of two related algal species to different concentrations of glufosinate, and to find some biochemical and metabolic parameters which may reliably indicate water pollution with this largely used herbicide.

\section{RESULTS AND DISCUSSION}

Growth rate of microalgal populations, which reflects the relation between formation of new algal individuals by cell division and death of senescent cells, is an important indicator of living conditions that allow a certain rhythm of development, its dynamics being a determinant factor for the efficiency of bioaccumulation and biotransformation of polluting agents during natural decontamination of polluted waters. In the case of Scenedesmus acuminatus (which has typically smaller cells than Sc. opoliensis), a very small concentration $0.1 \mu \mathrm{M}$ of the herbicide glufosinate induced a temporare decrease in cell density, which was followed by a recovery of the number of individuals in a unit of water volume (Fig. 1). $1 \mu \mathrm{M}$ glufosinate caused a longer decay of net reproductive rate, but in eight days it also allowed a recovery of cell density to values comparable with the non-treated control cultures. Exposure to $10 \mu \mathrm{M}$ glufosinate led to a rapid populational growth inhibition, followed by stabilization at this lower cell density. High concentration of the herbicide $(100 \mu \mathrm{M})$ exerted a progressive inhibition of algal multiplication, reflected by a gradual decrease of cell number as exposure time got longer. This dynamics of cell density of algal cultures reflects that this alga gives a differential response to different concentrations of the same herbicide dissolved in its aqueous environment.

Scenedesmus opoliensis responded to low concentration of glufosinate $(0.1 \mu \mathrm{M})$ by a quick decrease in cell density, followed by a transitory recovery, and then by a new phase of decline after four days of exposure (Fig. 2). This reflects that reproduction of this alga is more sensitive to low concentrations of the herbicide in comparison with the formerly presented one, thus being a better indicator for early detection of water pollution with this organic xenobiotic compound of agricultural origin. 
Very similar changes in cell density are also induced by exposure to $1 \mu \mathrm{M}$ glufosinate (rapid inhibition, recovery and another phase of decrement). As herbicide concentration gets as high as $10 \mu \mathrm{M}$, cell density decreases sharply during the first days of exposure, then it stabilizes at a lower value, and after four days it registers a further, but moderate and progressive decrement. In contrast, $100 \mu \mathrm{M}$ glufosinate causes a progressive decay of cell density during several days, followed by the set of a new steady-state at a low net rate of cell multiplication.

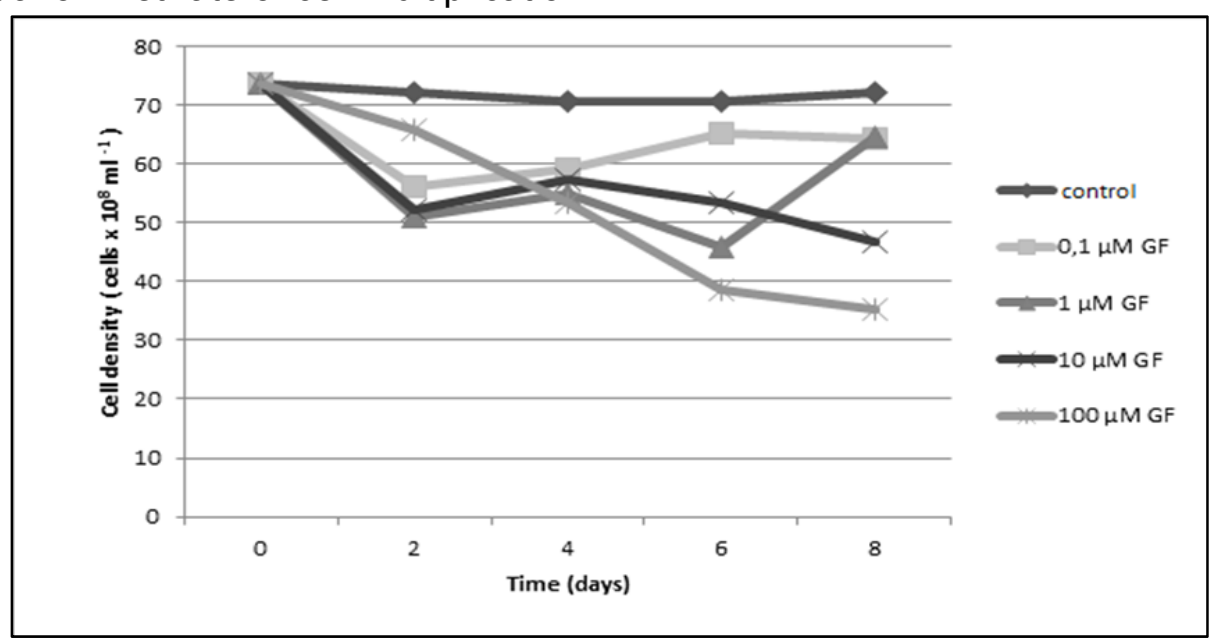

Figure 1. Dynamics of cell density in batch cultures of Scenedesmus acuminatus grown for 8 days in the presence of different concentrations of glufosinate $(G F, n=3)$

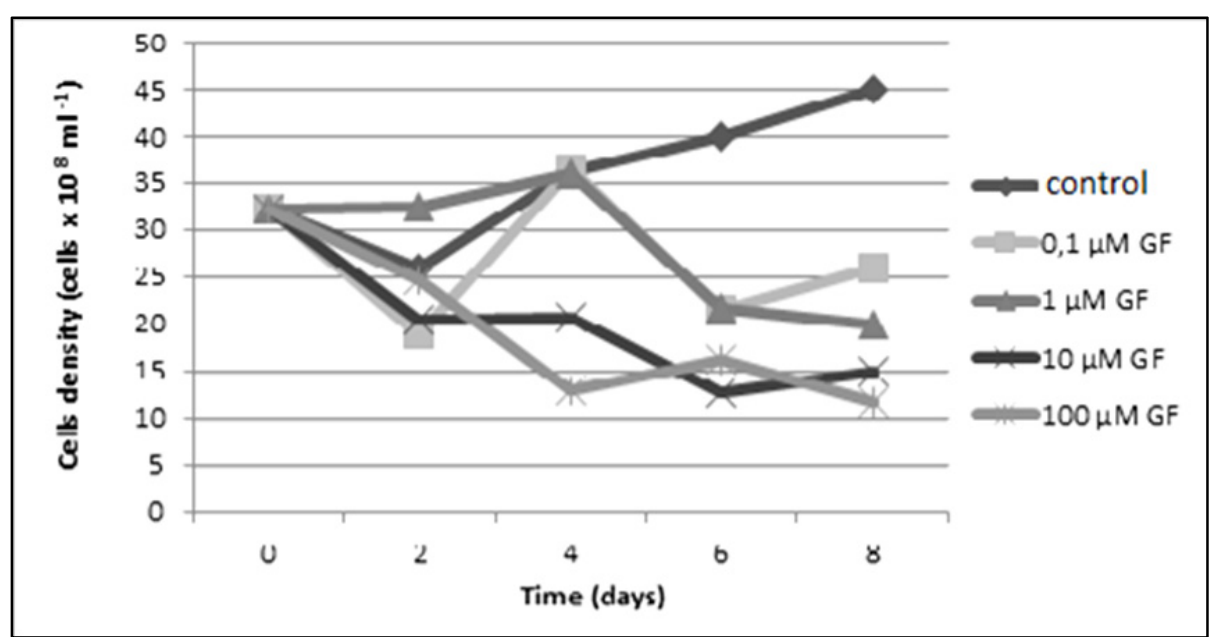

Figure 2. Variation of cell density in batch cultures of Scenedesmus opoliensis grown for 8 days in the presence of different concentrations of glufosinate (GF, $n=3$ ) 
Changes in the cell density of populations of the two algal species reveal different reactions in time to different amounts of the same herbicide, underlining the importance of reliable characterization and comparison of different species and strains during selection of the most suitable algae for indication and bioremediation of water pollution. Species-specific influence of herbicides on algal growth and reproduction were also reported by some authors [4]. Disturbance of cell division rate and induction of early senescence may be related to the indirect effect of glufosinate due to increased levels of ammonia in cell compartments where glutamine synthase is inhibited, and thus ammonium ions cannot be assimilated in glutamic acid [1].

If one compares the final cell density of populations of the two algal species after ten days of exposure to different glufosinate concentrations, without taking into account intermediary changes in cell number at different times of the period of treatment, it can be observed that in the case of Scenedesmus acuminatus $0.1 \mu \mathrm{M}, 1 \mu \mathrm{M}$ and $10 \mu \mathrm{M}$ glufosinate caused only a moderate decrease in final cell density, the amount of $100 \mu \mathrm{M}$ being the only one resulting in a more pronounced inhibition of net multiplication rate, while in case of Scenedesmus opoliensis all herbicide concentrations led to similar degrees of decrease in populational growth rate (Fig. 3). Extending the incubation time from 1 to 10 days, significantly increased the cell density of Scenedesmus opoliensis at the low levels of glufosinate but significantly decreased the cell density of Scenedesmus acuminatus at the high levels of glufosinate [20]. The results reflect that while exposure to low amounts of glufosinate is better indicated by $S$. opoliensis, $S$. acuminatus indicates more specifically the deleterious effects of high herbicide concentration after a longer exposure time.

Induced chlorophyll-a fluorescence measurement in the photosynthetic structures is a highly sensitive, accurate and non-damaging method for studying the efficiency of different steps of photochemical conversion of the absorbed light energy, as a prerequisite for sustained primary production of new organic compounds by fixation and reduction of carbon dioxide [5]. It provides information on the operation of the thylakoidal processes which constitute the light reactions of photosynthesis, as the only energy input for all living systems. From among the very numerous chlorophyll fluorescence parameters, which can be recorded or computed under various experimental conditions, we have chosen ground chlorophyll fluorescence (Fo) in dark-preadapted algal cells, on one hand because it is related to the very first steps of light energy harvesting and directional transfer in the photosynthetic pigment antennae, on which all the latter photochemical and assimilatory processes rely, on the other hand because it exhibited variations that are consistent with the impact of different amounts of herbicide in the aquatic environment. Fo values (expressed as relative fluorescence units which depend on light intensity and on chlorophyll content) 
change upon disturbances that occur in the functional organization of lightharvesting pigment-protein complexes that constitute the antennae of photosystem II in thylakoid membranes of chloroplasts, thus reflecting changes in the capacity of chlorophylls to absorb and to transfer light energy. In our cultures of Scenedesmus acuminatus the ground value of induced chlorophyll fluorescence exhibited a slight, but statistically significant decrease in the presence of $0.1 \mu \mathrm{M}$ glufosinate, while higher herbicide amounts caused an increase of Fo, this being more pronounced upon exposure to $1 \mu \mathrm{M}$ and to 100 $\mu \mathrm{M}$ glufosinate (Fig. 4). In Scenedesmus opoliensis the Fo was not influenced significantly by low concentrations of the herbicide, but exposure to $10 \mu \mathrm{M}$ and to $100 \mu \mathrm{M}$ of glufosinate resulted in a gradual decrease of ground fluorescence values with the increment of herbicide concentration. Thus, as far as Fo values are concerned, $S$. acuminatus is suitable for early detection of the influence of small herbicide amounts, while $S$. opoliensis is a better indicator of the degree of water contamination with glufosinate if its concentration reaches and exceeds 10 $\mu \mathrm{M}$. The results suggest that even if glufosinate is not a herbicide which inhibits photosynthesis, its influence on photorespiration and on the carbon assimilation in the Calvin cycle indirectly impairs organization and function of light-harvesting pigment-protein complexes. Accumulation of ammonium ions due to inhibition of glutamine synthase may also affect structure and permeability of thylakoid membranes where the light-harvesting antennae exist [8, 9].

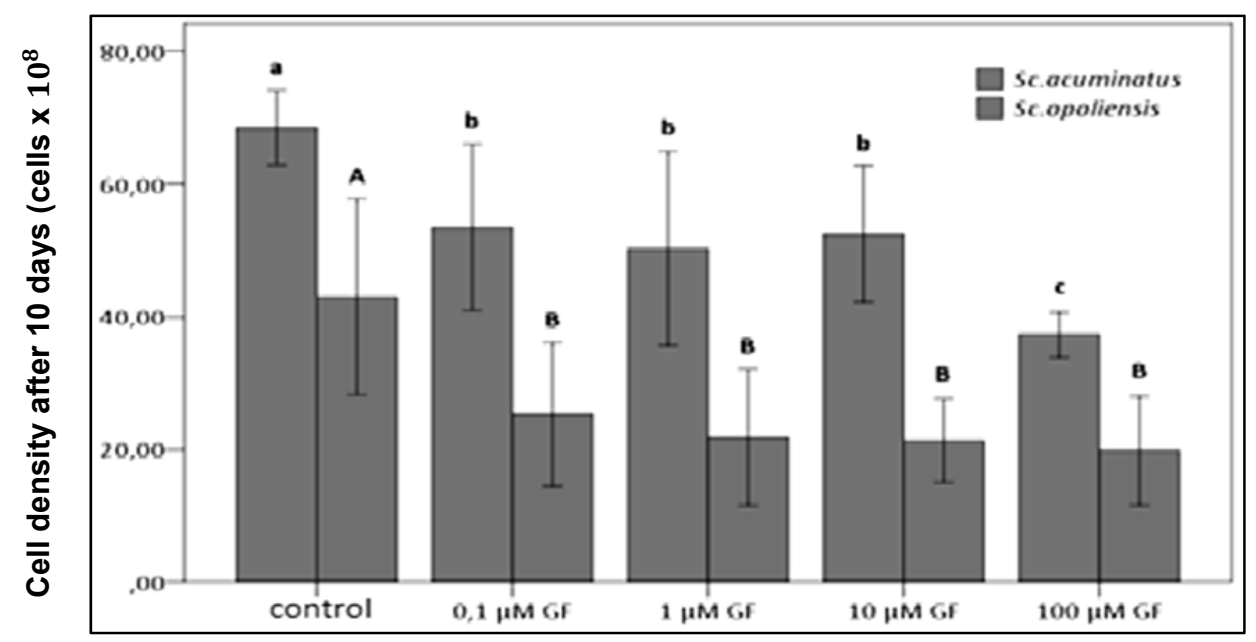

Figure 3. Final cell density in 10-days algal cultures exposed to various concentrations of glufosinate (GF) $(n=3$, vertical bars represent \pm SD from means, different letters indicate significant differences at $P<0.05$ between experimental variants of the same species) 


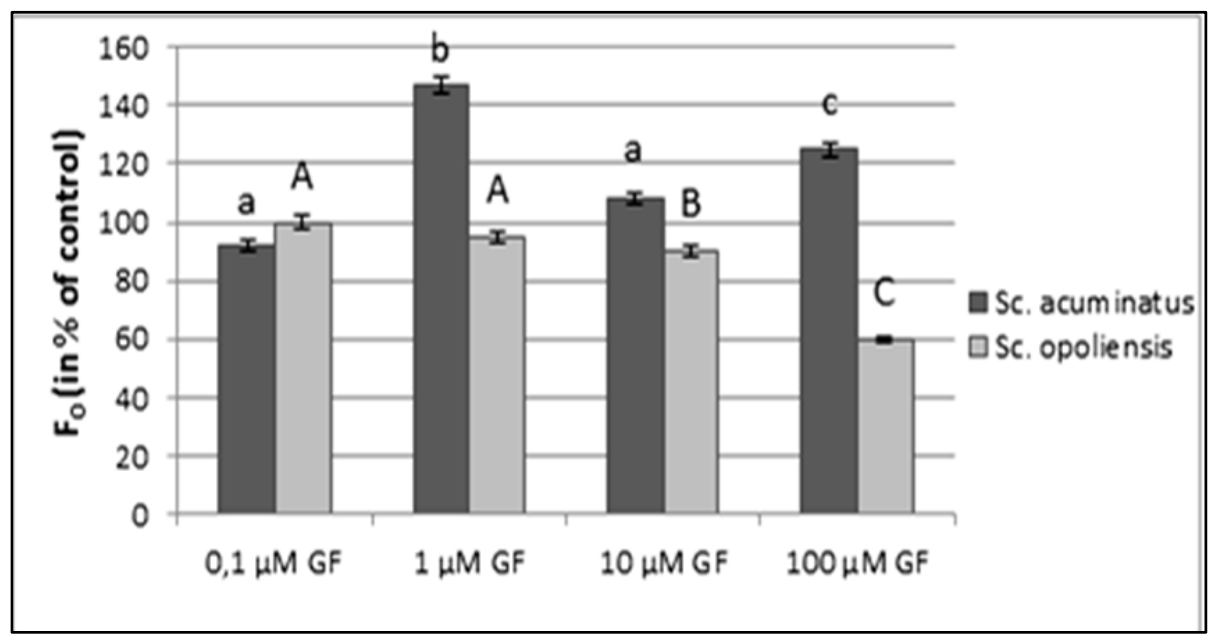

Figure 4. The induced ground fluorescence $\left(F_{0}\right)$ of chlorophylls, expressed as percentage of the control, in the algal cells exposed for one week to different amounts of glufosinate (GF) $(n=3$, vertical bars represent \pm SD from means, different letters indicate significant

differences at $P<0.05$ between experimental variants of the same algal species)

Ground chlorophyll fluorescence was also used to indicate and to evaluate the influence of other herbicides and water-pollutants on photosynthetic performance of several aquatic plants, but few chemical stress factors were found to significantly affect this parameter in a degree which is consistent with the severity of environmental stress or with the exposure time to water pollutants [6].

Quantity of photosynthetic pigments can be easily determined due to their specific absorption spectra. It varies in a large interval not only during acclimation of plants to different light intensities, but also under the influence of several chemical factors which inhibit steps of their biosynthetic pathway or enhance their catabolism. Because of their fundamental role in selective lightenergy harvesting, their quantity is related to the intensity of primary photosynthetic processes in the autotrophy of plants on which primary production relies. Chlorophylls ( $a$ and $b$ types in green algae and in higher plants) are the main light-harvesting pigments, but they are easily photooxidized under adverse conditions. Chlorophyll- $b$ is always present in smaller amounts than chlorophyll-a, and its quantity increases especially during acclimation to low photon flux densities. Carotenoid pigments (carotenes and xanthophylls) are mainly photoprotective molecules with high antioxidative capacity (especially against singlet oxygen, hydroxyl radical and alkylhydroperoxyl radicals), their concentration increasing under conditions when energy dissipation is needed in order to protect chlorophylls and other photosynthetic constituents from oxidative damage [7]. 
In the alga Scenedesmus acuminatus, chlorophyll-a content expressed on a dry weight basis moderately increased in the presence of $1 \mu \mathrm{M}$ glufosinate, and slightly decreased when the algal cells were exposed for several days, under constant illumination, to $10 \mu \mathrm{M}$ glufosinate. Very low and very high concentrations of this herbicide did not induce statistically significant changes in the chlorophyll-a content (Fig. 5). Quantity of chlorophyll-b exhibited a very similar pattern of variation with chlorophyll-a. Overall carotenoid pigment content moderately increased under the influence of $1 \mu \mathrm{M}$ and $10 \mu \mathrm{M}$ glufosinate in the aquatic environment. In the case of the species Scenedesmus opoliensis, chlorophyll-a content increased in the presence of 1 to 100 $\mu \mathrm{M}$ glufosinate (the highest concentration did not cause depletion of this pigment's content as in case of the other alga). The amount of chlorophyll- $b$ was augmented only by $1 \mu \mathrm{M}$ glufosinate, but did not show any correlation with herbicide concentration, thus being not a suitable biochemical marker for water pollution with this compound. Carotenoid pigment content was depleted in similar degrees by the different concentrations of glufosinate, so in the case of this alga carotenoid pigment content may indicate the presence of the herbicide, but not its quantity in the aqueous medium in which the algal cell live (Fig. 6). Our experimental results show that the amount of chlorophyll-a, exposed to the cultures of Sc. Opoliensis glufosinate is also increased by the 1 $\mu \mathrm{M}$ concentration because of the influence of the herbicide. At the same time, compared to the control as can be seen in Sc. Acuminatus cultures (Fig. 6), the treatment with the two largest glufosinate amount $(10 \mu \mathrm{M}$ and $100 \mu \mathrm{M})$ does not decrease neither the amount of chlorophyll-a and chlorophyll-b , nor the carotenoid pigments. Despite the fact that in the case of Sc. Opoliensis, the glufosinate-treated cultures did not reduce the amount of photosynthetic pigments in any of the variants, the values of $F_{0}$ and $F_{m}$ mutated to a certain extent impaired the organization of the antenna pigments and the energy transfer was more strongly inhibited.

To defend themselves, the algae supposedly increased the synthesis of photosynthetic pigment molecules.

If we compare variations in photosynthetic pigment content of the two algae, we can conclude that for $S$. acuminatus chlorophyll-a content, while in $S$. opoliensis the carotenoid content is a more adequate biochemical marker of water pollution with glufosinate.

The decreased chlorophyll content of plant cells exposed to glufosinate was partly explained by its strong inhibitory effect on synthesis of the chlorophyll precursor, 5-aminolevulinic acid [11]. When green microalgae were exposed to micromolar concentrations of the herbicide, their chlorophyll content (mainly the chlorophyll- $b$ concentration) exhibited a significant increase, because impairment of photochemical reactions of photosynthesis on the acceptor side of photosystem II resulted in an enhancement of the light- 
harvesting capacity, as algae tried to compensate energy deficiency by increasing the number of light-absorbing molecules [3],[16].

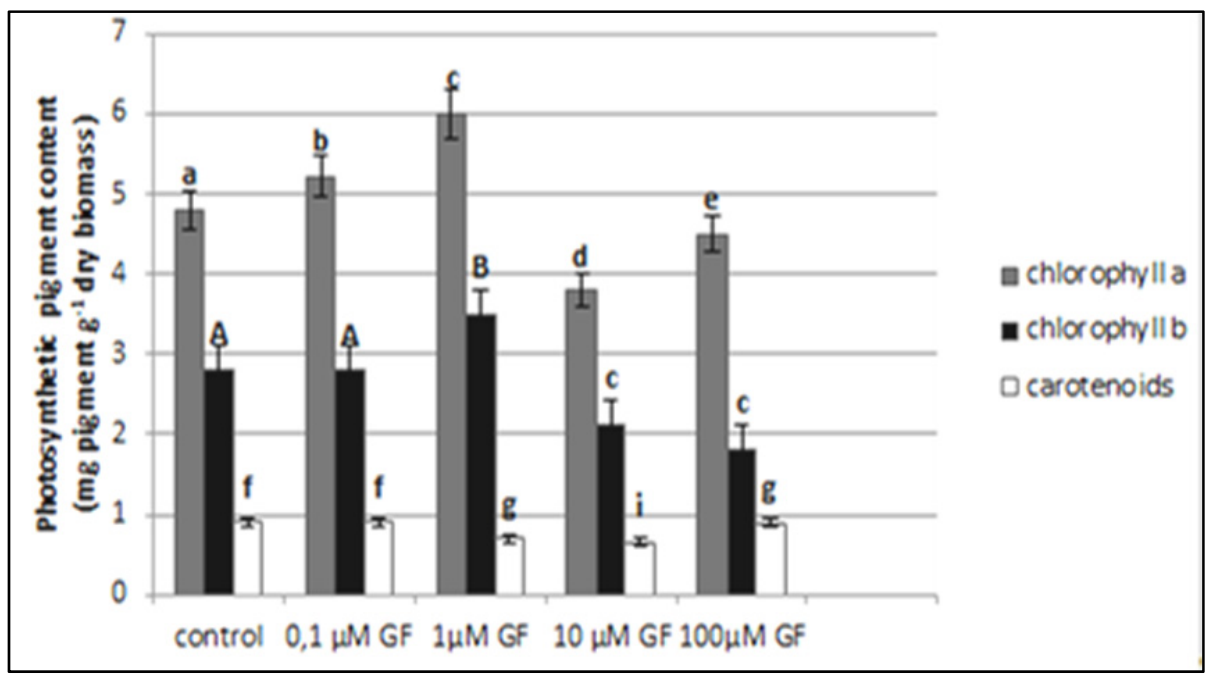

Figure 5. Effects of different concentrations of glufosinate (GF) on the photosynthetic pigment content of the green alga Scenedesmus acuminatus $(n=3$, vertical bars represent $\pm S D$ from means, different letters indicate significant differences at $P<0.05$ for the same pigment type)

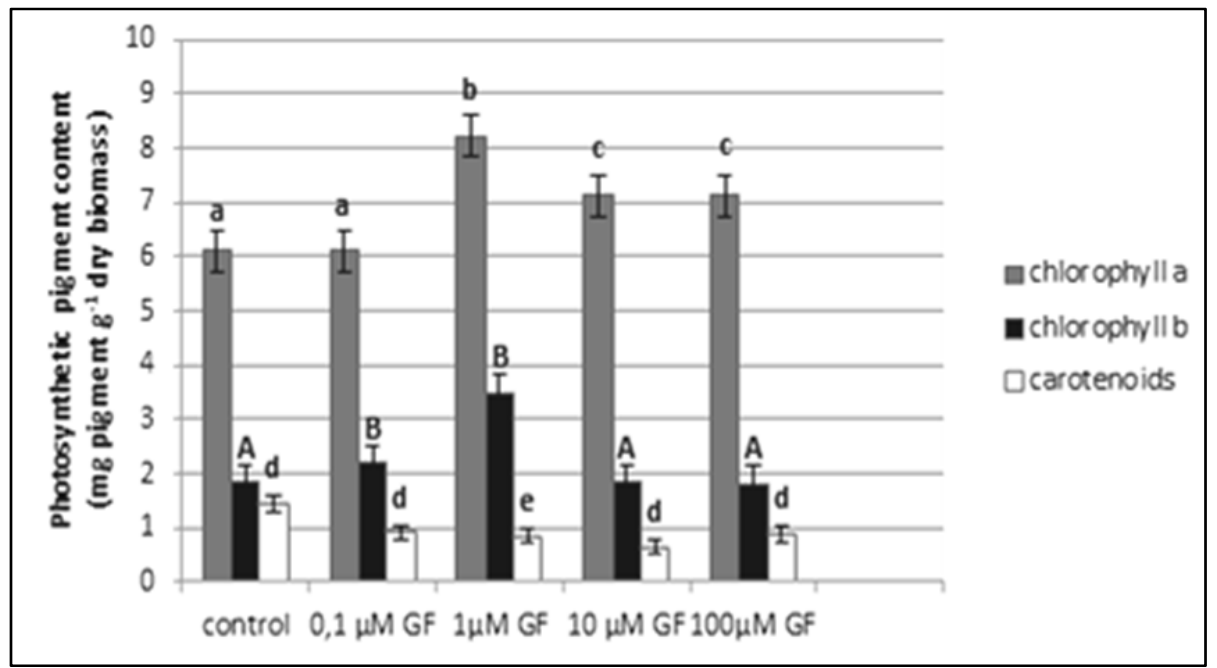

Figure 6. Effects of different concentrations of glufosinate (GF) on the photosynthetic pigment content of the green alga Scenedesmus opoliensis $(n=3$, vertical bars represent \pm SD from means, different letters indicate significant differences at $P<0.05$ for the same pigment type) 
These examples underline the finding that dynamics of different photosynthetic pigments may be differential markers for the influence of various chemical stress factors on plants living in polluted water [12].

\section{CONCLUSIONS}

Indicator organisms for water pollution with herbicides and other organic contaminants should be tested at species and intraspecific levels, because even related species, belonging to the same genus and living in similar aquatic environments, may exhibit differential biochemical and functional sensitivity. This is the case of the two Scenedesmus species from the freshwater green microalgae: S. acuminatus and $S$. opoliensis, the latter being more suitable for bioindication of water pollution with the herbicide glufosinate, considering changes induced in cell division rate, in chlorophyll and carotenoid pigment content of the cells, and in functional organization of the light-harvesting pigment antennae of the photosynthetic apparatus responsible for primary photochemical reactions. Monitoring changes of algal cell number at regular time intervals gives a better discrimination of herbicide impact than evaluation of final cell density after a certain period of exposure. Chlorophyll-a content varies in a greater extent under the influence of different herbicide concentrations than chlorophyll$b$ and carotenoid pigment contents do, thus being a better biochemical marker of algal reaction to water pollution with glufosinate. As a continuation of the present research, it is worth considering other biochemical parameters that do not show species-dependent differences, but more generally indicate the concentrationand time-dependent effects of certain water pollutants on the main primary producers of aquatic environments.

\section{EXPERIMENTAL SECTION}

Local strains of two green microalgal species, belonging to the same genus and widespread in variously polluted freshwater ponds: Scenedesmus acuminatus strain AICB 136 collected from the Tur creek near Cluj-Napoca, and Scenedesmus opoliensis strain AICB 141 originating in a pond of Săcălaia, Cluj county [5] were introduced in axenic monoalgal batch cultures, being grown in Bold's basal inorganic nutrient medium [14]. Cell cultures being at the beginning of the stationary phase of their population growth were used for initiation of the experiments. Both algal species were treated for ten days with $0.1 \mu \mathrm{M}, 1 \mu \mathrm{M}, 10 \mu \mathrm{M}$, and respectively $100 \mu \mathrm{M}$ of the herbicide glufosinate [ammonium salt of phosphinothricin, i. e. ammonium-(3-amino-3carboxy-propyl)-methyl phosphi-nate, dissolved in the sterile nutrient medium. Control cultures were grown in Bold's basal medium with no addition of herbicide. The initial $\mathrm{pH}$ value of all cultures was set to 5.6. The cultures were grown under constant environmental conditions in Certomat BS-1 algal growth 
chamber, at a photosynthetically active photon flux density of $130 \mu \mathrm{M}$ photons $\mathrm{m}^{-2} \mathrm{~s}^{-1}$, at $22{ }^{\circ} \mathrm{C}$, with horizontal shaking at $60 \mathrm{rpm}$ [6]. Cultures were set in three repetitions, and measurements were repeated three times.

Variations in the cell density of algal cultures were established with a periodicity of two days by cytometry, using Bürker's cell counter slide and a light microscope. This growth parameter reflects the capacity of microalgae to reproduce by cell divisions, i. e. to modify the number of individuals in a given volume of aqueous solutions[18].

Parameters of the induced chlorophyll-a fluorescence were recorded in vivo and in situ with a photosynthetic efficiency analyzer type fluorimeter (PEA from Hansatech, UK), in homogenized algal cell cultures adjusted to the same cell density, and dark-adapted for 5 minutes before measurement of chlorophyll fluorescence parameters by use of actinic light flashes with different intensities. The ground fluorescence (Fo) and the transitory maximal fluores-cence $(\mathrm{Fm})$ values were recorded, and the ratio between the variable and the maximal fluorescence $(\mathrm{Fv} / \mathrm{Fm}$, where $\mathrm{Fv}=\mathrm{Fm}-\mathrm{Fo})$ was calculated, this latter being correlated with the potential or maximal quantum yield of photosynthesis under the given developmental and metabolic conditions $[7,8,15]$. Because from the above-mentioned parameters ground fluorescence was found the most sensitive to the herbicide treatments, only this one was selected for presen-tation.

Photosynthetic pigments (chlorophyll- $a$, chlorophyll- $b$ and carotenoids) were extracted from the algae collected by filtration and dehydrated for three days at $80{ }^{\circ} \mathrm{C}$. After measurement of dry weight of the algal samples, extraction was performed for two days at room temperature and in darkness with dimethylformamide ( $5 \mathrm{ml}$ for each algal probe). Photosynthetic pigment content was determined photometrically, based on the absorbance of the algal extracts at wavelengths of $480 \mathrm{~nm}, 663.8 \mathrm{~nm}$ and $646.8 \mathrm{~nm}$ [10].

Experimental data were evaluated statistically (in $\mathrm{R}$ environment, $\mathrm{R}$ Development Core Team 2014), using one-way ANOVA and the post-hoc Tukey HSD test for establishing the significance of differences between treatments (normality of values distribution was established with the ShapiroWilk test, while homogeneity of variances was analyzed with Bartlett's test).

\section{REFERENCES}

1. C. Aflalo, W. Bing, A. Zarka, S. Boussiba, Zeitschrift fur Naturforschung Section C Journal of Biosciences, 1999, 54, 49.

2. N. Abdel-Raouf, I. B. M. Ibraheem, O. Hammouda, Eutrophication of River Nile as indicator of pollution. Al-Azhar Bulletin of Science, 2003, 293.

3. O. Aksakal, Acta Physiologiae Plantarum, 2013, 35, 2281. 
4. F. Araniti, A. Sorgona, A. Lupini, M. R. Abenavoli, Allelophathy Journal, 2002, 29, 107.

5. N. Dragoş, L. S. Péterfi, L. Momeu, C. Popescu, An introduction to the algae and the culture collection of algae at the Institute of Biological Research ClujNapoca, Cluj University Press, Cluj-Napoca, 1997, 197-200.

6. M.C. Falco, A. Tulmann Neto, E.C. Ulian, Plant Cell Reports ,2000, 19, 1188.

7. L. Fodorpataki, S. Barna, H. Deak, B. Kovacs, J. Geraj, B. Holinka, Analele Universității din Oradea, Fasc. Biologie, 2014, 21, 19

8. L. Fodorpataki, A. Márton, T Csorba, Contribuții Botanice, 2001, 36, 101.

9. L. Fodorpataki, C. Bartha, Z. G. Keresztes, Analele Universității din Oradea, Fasc. Biologie, 2009, 16(1), 51.

10. G. Horvath, M. Droppa, L. Fodorpataki, A. Istokovics, G. Garab, W. Oettmeier, Proceedings of the National Academy of the USA, 1996, 96, 3876.

11. G. S. Johal, D. M. Huber, European Journal of Agronomy, 2009, 31, 144.

12. V. Lozovaya, A. Ulanov, A. Lygin, D. Duncan, J. Widholm, Planta 2006, 224, 1385.

13. F.A. Macias, A. Oliveros-Bastidas, D.Marin, C. Carrera, N. Chinchilla, J.M. G. Molinillo, Phytochemistry Reviews, 2008, 7(1), 179.

14. F. Marva, V. Lopez-Rodas, M .Rouco, M. Navarro, F.J. Torro, E. Costas, A. Flores-Moya, Aquatic Toxicology, 2010, 96(2), 130.

15. N. Mallick, F. M. Mohn, Ecotoxicology and Environmental Safety, 2003, 55, 64.

16. J. Papp, L. Fodorpataki, Contribuții Botanice, 2002, 37, 231.

17. R. Prado, C.Rioboo, C. Herrero, A. Cid, Chemosphere, 2009, 76, 1440.

18. H. Scragg, A. M. Illman, A. Carden, S. W. Shales, Biomass and Bioenergy, 2002, 23(1), 67.

19. Ulanov, A.Lygin, D. Duncan, J.Widholm, V.Lozovaya, Journal of Plant Physiology, 2009, 167, 978.

20. S. Zhou, Y. Shao, N. Gao, Y.Deng, J. Qiao, H. Ou, J. Deng, Science of the Total Environment, 2013, 463-464, 111. 